\title{
Homologias entre a organização do espaço, relação entre colegas, com a clientela e com a lei em uma Delegacia de Mulheres
}

\author{
Homologies between the organization of space, relationship \\ between colleagues, with clients and with the law in a \\ police station for women
}

Miriam Steffen Vieira*

\begin{abstract}
Resumo: Este paper está referenciado numa etnografia da Delegacia da Mulher de Porto Alegre (2004-2006) e tem por objetivo analisar as concepções de agentes policiais sobre o trabalho que realizam. Primeiramente, apresenta as noções que embasam o projeto político que originou as delegacias de mulheres e as nuanças a partir das práticas de atendimento policial. Posteriormente, correlaciona diversos aspectos que integram este universo - organização do espaço, proximidade com a clientela e sua demanda, prestígio das funções e concepções de direito - para desenvolver o argumento da existência de uma hierarquia interna transposta na organização do espaço e também no processo de construção de categorias jurídicas no campo dos direitos das mulheres.
\end{abstract}

Palavras-chave: Antropologia do direito; Práticas de justiça; Violência contra as mulheres

\begin{abstract}
This paper, grounded in the ethnographic study of a Women's Police Station in Porto Alegre (2004-2006), proposes to analyze the way police agents view their work. First, we consider the notions that underwrite the political project that gave rise to the women's police stations and the nuances involved when putting these notions into practice. Subsequently, we correlate the diverse elements that compose this universe - spatial organization, proximity with the clients and their demands, prestige of rank and function, and notions of law - developing the argument that there exists an internal hierarchy transposed onto the spatial organization as well as into the process of constructing juridical categories in the field of women's rights.
\end{abstract}

Key words: Antropology of law; Practices of justice; Violence against women

* Pós-Doutoranda em Antropologia Social (CNPq), pesquisadora associada ao Núcleo de Antropologia e Cidadania, Naci/Ufrgs, Porto Alegre, Brasil.<misteffen@hotmail.com>

\begin{tabular}{|l|l|l|l|l|l|}
\hline Civitas & Porto Alegre & v. 8 & n. 3 & p. 482-497 & set.-dez. 2008 \\
\hline
\end{tabular}




\section{Apresentação}

Este trabalho parte de uma etnografia realizada na Delegacia da Mulher de Porto Alegre, RS, (2004-2006) $)^{1}$ e visa analisar o modo como esse universo legal ganha sentido a partir das práticas policiais, do seu contato cotidiano com a clientela ${ }^{2}$ e com as demandas que chegam nessa primeira instância do sistema de justiça. Apresento a seguir alguns ingredientes que compõem este universo institucional e que revelam uma dissimetria entre, de um lado, uma maior proximidade com a clientela, com o popular e com as pessoas logo que ocorreu o fato e, de outro, com o universo jurídico, as leis, as tipificações jurídicas e quem tem legitimidade para falar deste lugar. Argumento aqui pela existência de uma hierarquia interna transposta na organização do espaço e também no processo de tipificação penal.

\section{Delegacia da Mulher: um projeto político}

Delegacia para mulheres ${ }^{3}$ é uma política pública originada no Brasil e está intimamente relacionada à atuação feminista que enfocou a violência contra a mulher como uma estratégia política de visibilidade a este movimento social. Esta foi a pauta, dentro da agenda feminista de inícios dos anos 1980, que propiciou publicizar a desigualdade entre os sexos para além de seu "nicho" militante (Heilborn, 2000; Soares, 1999; Gregori, 1993; Grossi, 1994).

A primeira Delegacia da Mulher foi criada em 1985 em São Paulo (Saffioti, 2002, p. 61), sendo que atualmente o país conta com cerca de 400 Delegacias (Bonetti, Pinheiro e Ferreira, 2008). Na apresentação da "Norma Técnica de Padronização: Delegacias Especializadas de Atendimento à Mulher" (DEAMS) a Ministra Nilcéia Freire, responsável pela Secretaria Especial de Políticas para as Mulheres (Ministério da Justiça/Secretaria Nacional de Segurança Pública), diz que a Norma visa implementar a

1 Este artigo resume o conteúdo de um dos capítulos da Tese de Doutorado em Antropologia Social/Ufrgs (Vieira, 2007). Agradeço a todos os agentes policiais e funcionários desta delegacia pelo acolhimento, por compartilharem generosamente o seu cotidiano de trabalho e por terem aberto as portas deste serviço à pesquisa.

2 O destaque em itálico está sendo usado ao longo do texto para indicar expressões êmicas.

3 A Polícia Civil, no Estado do Rio Grande do Sul, está organizada em Departamentos, sendo que as Delegacias de Mulheres estão no Departamento de Polícia Metropolitana, na Divisão de Polícia Distrital, que contempla as Delegacias de Polícia que circunscrevem determinados territórios. No Estado do Rio Grande do Sul, são chamadas de Delegacia da Mulher (DM), em São Paulo Delegacia de Defesa à Mulher (DDM) e no Rio de Janeiro são chamadas de Delegacias Especializadas no Atendimento à Mulher (Deam). A Norma Técnica do Ministério da Justiça utiliza esta última denominação. 
"Política Nacional de Enfrentamento à Violência contra a Mulher" e surge "no marco da celebração dos 20 anos de existência da primeira política pública de enfrentamento da violência contra a mulher: as Deams" (2006, p. 12). Como diretrizes, a Norma define que as Deams são "unidades especializadas da Polícia Civil para o atendimento especializado à mulher em situação de violência de gênero" (2006, p. 24). Ou seja, trata-se de um serviço especializado em um dado "problema social” e voltado a um público específico.

A Delegacia da Mulher de Porto Alegre foi criada pela Portaria 19/1988, publicada no Diário Oficial do Estado do Rio Grande do Sul, visando o atendimento a mulheres entre 18 a 60 anos. Está em sintonia com as lutas sociais que impulsionaram a sua criação e com as regulamentações em torno desta política pública. Em entrevista, a delegada em exercício manifestou sua concepção de delegacia de mulher:

A gente incentiva [o registro na Delegacia] através de palestras e dos meios de comunicação. A gente tem que dar um retorno para essas mulheres, então o nosso objetivo é deixar o local mais aconchegante, mais propício para que ela faça o registro. [...] A gente também tem projetos para tentar aproximar o nosso trabalho com o Centro de Referência da Mulher, porque o nosso papel encerra aqui, mas a mulher necessita de vários outros profissionais dessa área que trabalha com violência contra as mulheres: ela vai precisar de um advogado, vai precisar de um psicólogo. Então [é importante] aproximar a Delegacia desses outros órgãos. A gente está tentando trazer eles até aqui, pelo menos duas ou três vezes no mês, para que facilite esse deslocamento, para que a mulher não precise se deslocar até o Centro de Referência para ter atendimento com a psicóloga ou advogada. Algumas ONGs também virem para cá, como já foi feito, trazerem informações sobre saúde da mulher; porque é um trabalho que tem que ser conjunto. A violência contra as mulheres não se encerra na Delegacia, tem vários órgãos; então a gente tem que tentar aproximar a Delegacia desses outros órgãos (Entrevista, 10.04.06).

Diversas falas da Delegada Alice ${ }^{4}$ reforçam esta especificidade da demanda para a qual o serviço foi criado - violência contra mulheres - e as necessidades que requer: ser um local aconchegante, propício para que ela faça o registro, realizar um trabalho em conjunto com outros órgãos, bem como envolver outras formações profissionais - psicólogo e advogado - que trabalham na área. Deste modo, a especialização do serviço parece

\footnotetext{
4 Por questões éticas da pesquisa, os nomes são fictícios, visando a não identificação de agentes do campo como também de partes implicadas em registros de ocorrência policial.
} 
introduzir algumas novidades na concepção do trabalho policial. Refiro-me aqui a idéia de social presente neste espaço. Antes de ingressar na Delegacia da Mulher, a atual delegada passou por duas distritais (no interior e na área metropolitana), por um posto de atendimento à mulher e pela Delegacia do Idoso; com base nesta experiência, faz uma diferenciação do trabalho realizado nestas delegacias:

A Delegacia da Mulher, a do Idoso, não deixam de ser uma delegacia, porque todas trabalham com o crime, só que além do papel de apuração dos crimes, ela tem um papel social que difere das demais delegacias. As demais também têm papel social até porque há uma participação do delegado geralmente em eventos do grupo local onde ela atua, mas a da Mulher e do Idoso é bem mais social do que as demais delegacias. (...) Social, no sentido de não só apurar os crimes, mas também de divulgar os direitos relativos à mulher, ao idoso, a prevenção desses crimes, orientação através de palestras, de comparecimento em unidades de saúde. Então é um papel social mais do que as demais delegacias (Entrevista, 10.04.06).

Chamo atenção aqui para a idéia de social no trabalho da Delegacia da Mulher. Ao reconhecer a sua especificidade, considerando-a como um serviço especializado em violência contra a mulher, a delegada também destaca o caráter social do trabalho, qual seja, divulgar os direitos relativos à mulher e realizar um trabalho de prevenção e de orientação através de palestras em entidades sociais e de serviços públicos. Esta idéia de trabalho social ligado à divulgação, prevenção e orientação sobre direitos, especificamente sobre violência contra a mulher, bem como os aspectos anteriormente mencionados - trabalho em rede e o seu caráter multidisciplinar, está em sintonia com o atual processo de judicialização de conflitos interpessoais, que tem no horizonte um discurso legalista que reforça o papel do judiciário e do conhecimento da lei para a garantia dos direitos (Rifiótis, 2003; Debert, 2006). Trata-se aqui de uma noção de social que passa pela linguagem dos direitos. Como tal concepção aparece nas práticas e no cotidiano de trabalho das diferentes agentes policiais que atuam neste espaço?

\section{Negociando a ambigüidade com a clientela: aqui a gente faz mais é serviço social}

Esta concepção de que além da apuração de crimes, a Delegacia possui uma função social, associada a uma linguagem jurídica, voltada à prevenção, orientação e garantia de direitos, foi enfatizada na fala da Delegada. Esta 
percepção adquiriu outras nuanças principalmente junto às plantonistas que realizam a recepção e o registro das ocorrências.

A frase aqui a gente faz mais é serviço social foi utilizada por uma escrivã que atende no Plantão, Nadir, quando explicava sobre o tipo de trabalho ali realizado (Diário de Campo, doravante denominado "DC", 12.11.04). A idéia de social parece estar aqui relacionada ao tipo de atendimento prestado na Delegacia da Mulher, como definiu uma plantonista aqui é todo o tipo de registro em que a mulher é a vítima. Nesta definição podemos perceber um alargamento das atribuições da Delegacia em correspondência à diversidade de demandas recebidas. Importa ressaltar aqui este reconhecimento acerca dos direitos das mulheres, seguramente um efeito do investimento feminista no campo legal, mas que revela um ganho para além das demandas pontuais que compõem a agenda política deste movimento social: trata-se aqui da legitimidade de um novo espaço político referente aos direitos da mulher.

Um primeiro aspecto a ser enfatizado nas concepções da Delegacia pelas agentes policiais é o seu reconhecimento como um espaço para a mulher, um lugar onde ela pode procurar seus direitos (DC, 12.01.06), ou seja, um reconhecimento para além do "problema social" que a originou. Este aspecto está representado nos dados quantitativos dos atendimentos policiais do ano de 2003, sendo a terceira principal categoria de classificação o "fato, em tese, atípico", que reúne os registros não tipificados no Código Penal, totalizando 654 dos 7065 Boletins de Ocorrência daquele ano, perdendo apenas para "lesão corporal", com 2595 e "ameaça", com 2080 registros.

As práticas de atendimento na Delegacia da Mulher aqui em pauta se assemelham ao contexto descrito por Muniz (1996), porém, menos do que uma "negociação entre participantes" (com base na prática da "acareação" ou da "mediação"), caracteriza-se pela prática do "aconselhamento", que vai desde a escuta, orientações sobre princípios legais e possibilidade de enquadramento jurídico, como também sobre os seus limites. Neste sentido, apresenta-se como uma construção a partir das possibilidades jurídicas no campo dos direitos da mulher.

Ao longo do trabalho de campo foi possível acompanhar diversos atendimentos em que predominaram as dicas e estratégias de usos dos recursos legais favorecendo aos interesses das mulheres. Por exemplo, no caso de um atendimento em que a cliente queria que o ex-companheiro saísse de sua casa e a agente policial sugeriu que ela fizesse um afastamento do lar, e explicou: "espera ele falar, que faça o escândalo dele. Chama a Brigada, faz a ocorrência e leva para a advogada, lá tu explica tudo, que tu 
não quer mais que ele pegue a criança, que ele não paga pensão, que faz ameaça" (DC, 14.10.04).

Também ocorria de agentes policiais alertarem quanto aos limites do judiciário, por exemplo, no caso de uma mãe que fora denunciar o filho, de 25 anos, que morava em sua casa e incomodava, era muito agressivo e estava envolvido com alguma coisa ilícita que parecia ser a venda de materiais roubados: "o negócio é o seguinte, vou ser bem sincera, porque mentira tem perna curta. Nós vamos registrar, vai ao juiz, vai resolver teu problema? Não. O juiz não vai falar com ele para ele mudar o comportamento, ele só vai responder pelo crime dele" (DC, 30.11.04). Enquanto preenchia o Boletim de Ocorrência, a atendente continuava explicando sobre o funcionamento do judiciário e esclareceu que para representar em juízo não precisava de advogado, mas sugeriu que ela buscasse este profissional para "aconselhar" o seu filho, o que não aconteceria no judiciário - daí a senhora vai ver a possibilidade de tirar o seu filho de casa.

Semelhante a este caso, também acompanhei mais dois de mães que foram buscar auxílio da Delegacia em função da coabitação conflituosa e agressiva com filhos maiores. Num desses casos, a mãe, professora aposentada, estava com receio de ver a filha presa, apenas queria que ela se transferisse para a casa do pai. Foi aconselhada a registrar "só para assustar, não precisa ir à justiça” (DC, 12.01.06), embora este uso da Delegacia seja muito criticado entre as agentes, conforme escutei em outro momento, em uma oitiva da denunciante de um caso de "atentado violento ao pudor" pelo padrasto: "Não existe susto! A Delegacia não é fantasma para dar susto! Se ele cometeu, ele pode ir preso!" (DC, 05.10.04). Entretanto, essa diversidade de estratégias que sobressaem a partir do contraste entre os casos mencionados, parece revelar um conhecimento que visa conciliar o interesse da clientela às possibilidades e limites do direito, como também uma certa avaliação sobre a gravidade do caso.

Além desta dimensão de negociação presente na busca de serviços jurídicos em defesa dos direitos da mulher, com estes exemplos busco chamar atenção para a dimensão construcionista das categorias jurídicas, e, neste processo, para o importante lugar ocupado pelas agentes policiais localizadas no plantão de atendimentos.

\section{Agentes policiais: atribuições e hierarquias funcionais}

Neste item apresento a estrutura organizacional da Delegacia, visando explicitar homologias entre a organização do espaço, hierarquia funcional e práticas de atendimentos policiais. 
A Delegacia foi composta por um quadro funcional de cerca de trinta pessoas ao longo da pesquisa, contando os que estiveram em licença saúde ou no aguardo da aposentadoria. Além da delegada, também atuam outras agentes policiais, funcionárias administrativas e estagiárias. As funcionárias administrativas foram agregadas à Secretaria de Polícia quando da extinção da Caixa Econômica Estadual e, por não serem concursadas como policiais realizam atividades auxiliares. No início da pesquisa havia duas funcionárias, ambas atuavam junto ao Plantão, fazendo trabalho de recepção, de escuta inicial e organização da espera pela ordem de chegada. Em 2006, uma delas passou a auxiliar as policiais do Cartório e a outra funcionária aposentouse. Havia três estagiárias de ensino médio, sendo um do sexo masculino, e que circulavam pelos vários setores, principalmente realizando trabalho de arquivo, de encaminhamentos internos e recepção. Em 2006 o número de estagiárias foi preservado, porém mudaram as pessoas, sendo uma estudante de direito.

Como policiais, estão os cargos de investigador, inspetor, escrivão e comissário. O primeiro cargo, que exigia nível fundamental de ensino, está em extinção desde meados dos anos noventa, não ocorrendo mais concurso e permanecendo apenas os agentes que já fazem parte do quadro funcional da polícia civil. A partir de 1998, o concurso público para escrivão e inspetor passou a exigir grau de instrução superior, não importando a área de formação. Assim, encontramos na Delegacia da Mulher policiais com níveis distintos de instrução, segundo o ano de ingresso, sendo que atualmente grande parte das policiais na ativa, nos diversos setores, tem curso superior, mesmo as mais antigas, que estão na Delegacia há mais de dez anos, deram continuidade aos estudos posteriormente, em diversas áreas como direito, pedagogia, psicologia, história, letras, educação física e nutrição.

Embora os cargos de inspetor e escrivão envolvam, em tese, atribuições distintas, no cotidiano de trabalho, segundo uma das plantonistas que entrou no último concurso para investigadora (1989), não tem diferença hoje em dia; "é que a escrivã normalmente fica no Cartório, tem um trabalho mais burocrático e a inspetora está mais no trabalho de investigação" (DC, 12.01.06); de modo que vamos encontrar esses cargos distribuídos nos diferentes setores da Delegacia. Muito embora as escrivãs estejam predominantemente no Cartório, setor responsável pela realização do Inquérito Policial ou Termo Circunstanciado - trabalho realizado dentro da Delegacia, como as oitivas das partes e testemunhas e coleta de provas - e as inspetoras na Seção de Investigação, que é o setor responsável por identificar a autoria dos crimes registrados na Delegacia - para isso realizam 
diligências, que é um trabalho de investigação realizado fora da Delegacia como percorrer o local do crime, buscar mais informações e testemunhas, além da realização de oitivas e recolhimento de indícios que possam contribuir com a realização do Inquérito.

O comissário é um cargo de promoção dentro da Policia Civil, "é como um sub-delegado, com a diferença que normalmente não tem curso superior" (DC, 23.07.04), conforme um policial empenhado em explicar-me a estrutura funcional da Polícia. Não existe concurso para comissário, mas a possibilidade de ascensão interna a partir dos cargos de escrivão e inspetor (Hagen, 2006).

A observação de campo se deu praticamente neste contexto funcional, no período de julho a novembro de 2004. Em 2005 fiz visitas esporádicas e, em 2006, retomei a observação com o objetivo específico de acompanhar o plantão de atendimentos. Em julho de 2005 trocou a delegada titular. Pouco antes desta mudança, saíram os dois comissários e, junto com a delegada mais duas policiais atuantes na Secretaria. A nova delegada, na faixa dos trinta anos, trouxe consigo três policiais: um escrivão para a Secretaria, Marcelo, jovem de uns trinta e poucos anos, com formação em psicologia, trabalhou anteriormente no Serviço de Assistência Social da Polícia Civil e na Delegacia do Idoso, rapidamente se inteirou do funcionamento da Delegacia e das especificidades de sua demanda, em 2006 pude ver seu nome como palestrante em eventos organizados pelo movimento de mulheres. Além deste agente policial para a Secretaria, também acompanharam a Delegada uma inspetora, alocada no Serviço de Investigação, a Djanira, formada em educação física, possuí um porte atlético, sempre com calça de brim e, quando em diligências era comum vê-la com um colete de brim escuro, sem mangas, por cima da camiseta, de forma a cobrir o revólver; e a jovem escrivã Daniela, da área do direito, e que foi para o Cartório depois de uma rápida passagem pelo Plantão.

A Delegada Alice manifestou o desejo de atuar em Delegacias de Polícia desde a faculdade. Formada em 1996, em seguida fez concurso público e ingressou numa Delegacia do interior do Estado e simultaneamente no Posto da Mulher daquela cidade (1999-2001). Posterior a isto, assumiu uma distrital na área metropolitana e, em seguida, a Delegacia do Idoso, onde permaneceu como titular por dois anos (Entrevista, 10.04.06).

Chamo atenção para esta mudança na composição da Delegacia: demonstra um rodízio entre agentes policiais locados em diferentes delegacias e um conseqüente rearranjo interno que varia de acordo com o novo contexto. Ressalto que as mudanças introduzidas nesta última troca 
de delegada apontam para o ingresso de agentes com escolaridade superior, sendo um em direito, além de agentes policiais específicos para a área da investigação, substituindo os então comissários.

Lembro aqui das pesquisas desenvolvidas por Hagen (2006) e Schuch (2005). A primeira, ao estudar a composição da categoria policial quanto às formas de recrutamento, perfil sócio-demográfico e formação profissional, no Rio Grande do Sul, conclui que a categoria passou por uma mudança ao longo dos últimos vinte anos: "os requisitos de seleção para o ingresso hoje são mais exigentes, a forma de seleção se tornou pública e o conteúdo do treinamento inicial passou a incorporar novos temas, ligados a questões como a promoção dos direitos humanos e a qualificação para o uso comedido da força" (Hagen, 2006, p. 278).

Em consonância com esta gradual modificação nas formas de recrutamento e também na própria visão de polícia - esta historicamente esteve mais vinculada à idéia de controle da população pelo Estado e não como um serviço voltado à sociedade para a resolução de conflitos Schuch, ao analisar a formação de um "campo de atenção ao adolescente infrator Pós-ECA" em diversos aparelhos jurídico-estatais, demonstrou como os agentes policiais da Delegacia da Criança e Adolescente de Porto Alegre com ingresso no início dos anos 2000 incorporaram um "novo estilo profissional", revelando uma mudança institucional no sentido de um

investimento muito específico na formação de um novo tipo de profissional, adequado às propostas "preventivas" do trabalho da polícia com crianças e adolescentes que, no caso em questão, está muito vinculado aos quadros dirigentes nas delegacias, cada vez mais associados a um discurso legalista dos "direitos da criança e do adolescente" e com pouca ênfase na prática concreta das experiências profissionais (2005, p. 107).

Essas leituras sobre as transformações no sistema de justiça, nomeadamente em instituições policiais, também cabem à Delegacia da Mulher. A seguir apresento a organização do espaço, a forma de relação entre colegas, com a clientela e com a lei/direito.

\section{Da Rocinha para Vieira Souto: organização do espaço e hierarquia funcional}

A Delegacia da Mulher de Porto Alegre fica junto ao Palácio da Polícia Civil do Estado do Rio Grande do Sul, local de fácil acesso através de transporte urbano que vem de diferentes regiões da cidade. Ao longo do trabalho de campo e da análise dos Boletins de Ocorrência, foi possível verificar que a 
Delegacia da Mulher é procurada por pessoas de cidades de fora de sua área de circunscrição, onde não existem delegacias para o atendimento à mulher. Estes casos são registrados e posteriormente encaminhados à delegacia da região onde ocorreu o fato. O mesmo procedimento é adotado para casos relativos a outras delegacias, como a do idoso ou da criança. Cabe destacar que a procura da Delegacia da Mulher em casos de violência contra a mulher, principalmente de violência sexual, ocorreu também em casos envolvendo crianças ou idosos, sugerindo o reconhecimento social deste espaço.

As instalações ocupam o espaço de uma quadra e, além da parte administrativa da Secretaria de Polícia, contemplam ainda a área judiciária (onde são realizados os flagrantes e os reconhecimentos), as delegacias da mulher, do idoso, do trânsito, de tóxicos e a de homicídios, além de um pátio interno para as viaturas. O Departamento Médico Legal fica no prédio ao lado, facilitando a realização de exames periciais, necessários após um registro de ocorrência policial.

Quando fiz o primeiro contato, a delegacia estava mudando para um local mais amplo, mas a organização espacial seguia o mesmo princípio, correspondendo ao percurso dos registros e também à hierarquia funcional: inicia pelo plantão de atendimentos e, ao fundo e de acesso restrito, o cartório, onde os registros de ocorrências ganham a forma de inquéritos policiais ou termos circunstanciados para então serem distribuídos aos fóruns. Entre uma extremidade e outra, estão a secretaria, a seção de investigação e o gabinete da delegada. A seção de investigação fica em frente à secretaria e tem porta interna de acesso ao plantão e ao arquivo, sendo que deste pode se acessar facilmente o gabinete e o cartório. A secretaria e o gabinete também estão interligados, sendo que a primeira tem um guichê de comunicação com o público e o gabinete tem a entrada pelo cartório.

É no plantão onde ocorre o primeiro contato com a clientela, como é chamado o público que freqüenta a delegacia em referência principalmente às mulheres que vão realizar os registros, mas também aos homens que comparecem para prestar depoimentos e pedir informações. Conforme aponta a bibliografia e também o trabalho de campo ali realizado, o público que procura a delegacia procede de setores mais baixos, embora venha se ampliando para os setores médios, mulheres cursando faculdade e profissionais liberais.

No período da pesquisa, o plantão estava coberto por quatro equipes de trabalho que se revezavam em um regime de 24 horas de atividades e 72 horas de folga, envolvendo cerca de onze policiais como plantonistas, sendo um do sexo masculino. Além das plantonistas, atuam neste setor mais duas 
funcionárias com horário regular, uma para o turno da manhã e a outra para o turno da tarde, ou então estagiárias.

Embora praticamente todas as agentes tenham passado pelo Plantão em suas trajetórias profissionais, foi recorrente a percepção de que este não era um setor de reconhecimento entre os pares. Uma das motivações destacadas pelas agentes policiais para este desprestígio estava relacionada ao grau de instrução. Como falei anteriormente, é recente a obrigatoriedade de instrução superior para os cargos de escrivã e inspetora, e que embora o cargo de investigadora, cuja exigência era o ensino fundamental, já fora extinto, convivem na delegacia agentes que ingressaram em diferentes concursos e, portanto, com graus de instrução distintos. Foi no plantão onde encontrei um número menor de agentes com curso superior: de onze plantonistas atuantes em 2004, quatro não tinham instrução superior. Assim, ao conversar com duas plantonistas, a Viviane (escrivã de 2으 grau) e a Diná (investigadora de 6 음au), perguntei se no plantão precisava de curso superior, o que teve uma reação rápida e furiosa de Viviane: "até tu discriminando o plantão!" (DC, 12.01.06), demonstrando esta percepção do desprestígio da função de plantonista.

É neste contexto que a expressão da Rocinha para Vieira Souto ganha sentido. Utilizada pela funcionária administrativa Lídia quando transferida do plantão para o cartório, num dia de muito calor, ela estava sentada em uma das salas do cartório, com ar condicionado - no plantão tem ventilador de teto - carimbando e ordenando procedimentos policiais (DC, 09.01.06). A expressão ilustra bem a percepção local sobre os dois setores e está manifesta nos desabafos que acompanhavam algumas reclamações das plantonistas: "a gente é ralé mesmo, a gente não tem espaço, isso cansa" (DC, 16.09.04). Além disso, o contraste que sugere entre favela e elite expõe o componente classista presente na organização do espaço e no prestígio da função de acordo com a proximidade com o popular e com os seus dramas, "o plantão é o lugar onde a gente tem um contato mais direto com as pessoas. É o mais desgastante. Porque a pessoa chega logo após que ocorreu o fato, então, para a pessoa que trabalha no plantão é mais desgastante" (Delegada Alice, 10.04.06).

Esta percepção interna à delegacia sobre o plantão de atendimentos se assemelha em muito às colocações de Mariza Corrêa sobre a hierarquia profissional dentro do sistema de justiça. No caso desta Delegacia da Mulher, o plantão pode ser entendido como o ponto extremo nesta gradação de prestígio que alia nível de instrução, proximidade com a demanda e com os "transgressores da lei". Ao abordar a hierarquia entre os "manipuladores 
técnicos" no sistema de justiça, Corrêa destaca a relação entre delegados e juízes:

Os delegados são bacharéis em Direito e estão na base do triângulo da carreira judiciária, posição expressa não apenas pelos salários que recebem, menores do que os de seus colegas juízes ou promotores, mas também no fato de que eles são os intermediários entre a justiça e os transgressores da lei, os encarregados do trabalho de limpeza e triagem dos casos de violação das regras sociais estabelecidas (Corrêa, 1984, p. 48).

Dentro dessa idéia mais geral que relaciona prestígio profissional com proximidade dos(as) "transgressores da lei" e da demanda logo após que ocorreu o fato também podemos olhar para a relação entre comissariado e delegada. O comissariado não precisa de curso superior, mas em relação aos demais policiais, é o cargo que recebe um salário mais próximo ao de um delegado (Hagen, 2006). Atuam na Delegacia da Mulher três comissários: uma mulher, uma das mais antigas ali, é formada em Direito e trabalha junto ao cartório, auxiliando na elaboração dos relatórios dos inquéritos, e dois homens que ficam na seção de investigação. Esses últimos, por volta de 50/60 anos, sem curso superior e perto da aposentadoria, saíram da delegacia pouco antes da mudança da delegada, em meados de 2005. Interessa aqui a função ocupada por estes dois comissários responsáveis pela Seção de Investigação, menos pelas atribuições do setor do que pelo lugar que ocupam esses agentes no cotidiano da Delegacia da Mulher.

O Comissário Peixoto, um senhor alto e volumoso, com a pele muito branca e constantemente avermelhada, de rosto arredondado e olhos pequenos, o sorriso toma conta do rosto. Ele veio do interior para seguir carreira militar, já trabalhou em diversas delegacias e, por problemas de saúde, após infarto, ele se transferiu de uma distrital para a Delegacia do Idoso (DC, 18.08.04). Compondo este cenário acolhedor, era a ele que recorriam quando chegavam os casos considerados mais difíceis, que exigiam uma escuta pacienciosa. Volta e meia escutava as policiais se referirem a alguém como treze, ela é trezona diziam de alguém que julgavam com uma demanda incompreensível, que não fala coisa com coisa. Era ao comissariado que as plantonistas recorriam nesses casos, especialmente ao Comissário Peixoto. Transcrevo a seguir alguns trechos de um desses atendimentos:

Eu estava trabalhando nas ocorrências quando chegou uma das atendentes do Plantão para conversar com o Comissário Peixoto tem um caso que o comissário precisa me ajudar, e puxa ele para um canto falando bem baixinho e em seguida conduz uma senhora e uma menina para sala. A senhora aparentava uns 70 anos, 
pequeninha e magrinha, um pouco corcunda, vestia roupa em algodão, uma saia bem longa e uma tamanca sem saltos. Não usava bolsa, mas um grande saco. A jovem vestia calça de brim e camiseta. O Comissário disse que elas poderiam passar e as atendeu num espaço no fundo do Setor de Investigação (SI). Eu escutava apenas algumas palavras que revelavam que se tratava de violência sexual. Há quanto tempo ele fazia isso? A menina respondeu: todos os dias, e a senhora acrescentou é um velho tarado! As duas falavam ao mesmo tempo, falavam muito e, de vez em quando o comissário fazia alguma pergunta. Volta e meia ele levantava e caminhava na sala, ia até a porta, coçava a cabeça e sentava novamente. Fazia expressões de que não sabia o que fazer. Uma hora ele levantou e foi conversar com a inspetora, que estava em uma mesa ao meu lado. É meio confusa a coisa. Conta que a menina saiu de casa para morar com o namorado, mas quem comia ela era o sogro. Quando o marido ficou sabendo não quis mais ela. O palavreado é da vó! São duas peças essas duas, ele comentou comigo enquanto coçava a cabeça. A escrivã Andréia sugeriu que ele encaminhasse à Delegacia da Criança e do Adolescente, mas ele disse que ela fez 18 anos recentemente, que é ali mesmo. Ele volta para conversar com as demandantes e em seguida as encaminha ao Plantão para fazerem a ocorrência, diz que é um caso de estupro e de seqüestro. Aconselha a menina para contar tudo direitinho, que não precisa mentir, tem que falar direitinho o que aconteceu, que é para registrar. Depois o comissário fica conversando comigo e com a inspetora. Diz que é um caso complicado, porque envolve seqüestro, que a mantinham presa em casa, mas ela conseguiu sair e foi para casa da avó. Ele ri e após um tempo diz: na verdade o caso é muito triste, e pergunta para Andréia se ela sabe onde elas moram, comenta que deve ser um barraco menor que esta sala, acho que de chão de barro. Ela (a avó) recebe 500 reais e tem cinco pessoas para sustentar. É a pobreza! (DC, 24.08.04)

Este atendimento exemplifica um pouco esta função exercida pelo comissário, que procura de alguma forma compreender a queixa e identificar violações de direitos, ainda que o caso tenha envolvido aspectos morais e valores distintos dos seus. $\mathrm{O}$ conhecimento da realidade da pobreza era um dos assuntos prediletos deste comissário, permitindo uma contraposição em relação ao trabalho de outras policiais - "sabe que muita gente aqui nunca foi nas vilas", comentou certa vez (DC, 18.08.04). Foi também este comissário quem alertou sobre a proximidade entre policiais e marginais, que estes compõem a clientela da Delegacia e muitas das gírias policiais advêm deste contato: "o marginal tem uma linguagem muito rica. Nós convivemos com ele, ele é o nosso cliente. É uma troca de cultura” (DC, 20.08.04). 
A partir da atuação deste comissário, assim como da percepção local sobre o plantão de atendimentos, foi possível identificar alguns ingredientes que compõem este universo institucional e que revelam uma dissimetria entre, de um lado, uma maior proximidade com a clientela e com as pessoas logo que ocorreu o fato e, de outro, a "lei", as "tipificações jurídicas" e quem tem legitimidade para falar deste lugar. Em uma delegacia, este é o papel ocupado pela delegada, a quem cabe corrigir as tipificações jurídicas feitas no Plantão - porque às vezes é falsa, não corresponde a real tipificação - para então encaminhá-las ao setor responsável pelos procedimentos policiais, conforme esclareceu a delegada Alice (DC, 09.01.06). Ressalto aqui o lugar do direito e das leis no cotidiano de trabalho das agentes policiais, implicando em hierarquias funcionais que ultrapassam os limites deste serviço em particular para a forma como se estrutura o sistema de justiça. Um aspecto ilustrativo disto foi, por exemplo, quando busquei uma definição do delito de "falsa denúncia" junto às agentes policiais e as duas com quem conversei consultaram outras colegas formadas em direito. Isso revela o complexo lugar do direito e da lei naquele espaço. Ilustra o modo como a grande margem de interpretações que acompanha os códigos legais pode ser utilizada para definir quem faz parte do campo, quem está autorizado às interpretações ou não. Revela o poder de excluir do campo quem, despojado do título e de sua legitimidade, se aventura à interpretação ou palpites que sempre estão sujeitos a serem desautorizados por quem de direito. Sobre este tema, consultar Bourdieu (1989) quando este define "campo jurídico", a partir do caso francês, como o "lugar de concorrência pelo monopólio do direito de dizer o direito, quer dizer, a boa distribuição ou a boa ordem, na qual se defrontam agentes investidos de competência ao mesmo tempo social e técnica" $(1989$, p. 212). No contexto da delegacia, o direito tem uma certa aura de sagrado e, ao mesmo tempo, este efeito "escorregadio" que, mesmo a agente policial formada em direito e requisitada para resolver a dúvida, retorna com o Código Penal em punho e procede a leitura do artigo em questão (DC, 08.10.04).

Entretanto, ainda que a adequação da demanda aos tipos penais fosse uma atribuição do posto mais alto na hierarquia funcional, argumento que o complexo trabalho de escuta, compreensão e tradução de demandas sociais para fatos legais ocorrem principalmente no plantão e no comissariado. Assim, as agentes localizadas numa posição inferior em relação ao prestígio interno, estão em uma posição privilegiada do ponto de vista da construção dos tipos penais. 


\section{Conclusões}

Neste texto procurei enfatizar o cotidiano de uma delegacia de mulheres a partir das práticas de atendimento policiais - são estas que dão sentido às leis e que possibilitam a adequação de uma vasta demanda aos tipos penais possíveis. A partir deste enfoque nas práticas de justiça, que estou chamando de "universo legal em ato", destaquei alguns aspectos que incidem sobre a construção de categorias jurídicas no âmbito da violência contra as mulheres.

Primeiramente, destaquei as distintas percepções sobre a Delegacia de Mulheres, sendo que as práticas de atendimento policial revelam uma abrangência da delegacia para além do projeto político que a originou - violência contra as mulheres -, abrigando uma ampla demanda de orientações sobre direitos das mulheres.

Em um segundo momento, procurei estabelecer alguns paralelos entre a organização do espaço, hierarquia funcional e efeitos nas definições jurídicas. Neste sentido, esbocei uma imagem um tanto caricatural da delegacia. Entretanto, em diversos momentos ao longo do trabalho de campo esta me pareceu uma forma de demarcar o distanciamento social entre os dois pólos, demonstrando sua pertinência para entender aquele universo, como também contribuiu para evidenciar o lugar do direito, dos códigos de leis e dos saberes legais, sendo estes somente outorgados a quem de direito (Bourdieu, 1989). Em contraposição a este alto prestígio ligado ao saber jurídico, no bojo do processo de tipificação jurídica, se encontram as agentes policiais que recepcionam as demandas - as plantonistas - $\mathrm{e}$ que são as responsáveis pelo primeiro atendimento e pela realização do registro de ocorrência policial; assim como do comissariado, que realiza uma contextualização dos casos a partir da escuta e, mesmo, de um conhecimento prévio sobre a clientela que freqüenta aquele espaço. Argumentei que esses agentes são figuras centrais do ponto de vista deste processo de construção dos tipos penais e, por conseguinte, da própria definição dos limites deste campo voltado aos direitos das mulheres.

\section{Referências}

BRASIL. Ministério da Justiça. Secretaria Nacional de Segurança Pública. Secretaria Especial de Políticas para as Mulheres. Norma Técnica de Padronização: Delegacias Especializadas de Atendimento à Mulher (Deams). Brasília, 2006. Disponível em: <http://200.130.7.5/spmu/docs/Normas_deams.pdf $>$. Acesso em: 15 jun. 2007. 
BONETTI, Alinne de Lima; PINHEIRO, Luana; FERREIRA, Pedro. Violência contra as mulheres e direitos humanos no Brasil: uma abordagem a partir do Ligue 180. Brasília, 2008. (mimeo)

BOURDIEU, Pierre. A força do direito: elementos para uma sociologia do campo jurídico. In: O poder simbólico. Rio de Janeiro: Bertrand, 1989.

CORRÊA, Mariza. Morte em família: representações jurídicas de papéis sexuais. Rio de Janeiro: Paz e Terra, 1984.

DEBERT, Guita Grin. As Delegacias de Defesa da Mulher: judicialização das relações sociais ou politização da justiça? In: CORRÊA, Mariza; SOUZA, Érica Renata de (Orgs.). Vida em família: uma perspectiva comparativa sobre "crimes de honra". Campinas: Pagu - Núcleo de Estudos de Gênero, 2006. p. 15-38. (Coleção Encontros)

GREGORI, Maria Filomena. Cenas e queixas: um estudo sobre mulheres, relações violentas e a prática feminista. Rio de Janeiro: Paz e Terra/Anpocs, 1993.

GROSSI, Miriam Pillar. Novas/velhas violências contra a mulher no Brasil. Revista Estudos Feministas, Florianópolis, v. 5, n. especial, p. 473-483, 1994.

HAGEN, Acácia Maria Maduro. O trabalho policial: estudo da polícia Civil no estado do Rio Grande do Sul. São Paulo: Ibccrim, 2006.

HEILBORN, Maria Luíza. Violência e Mulher. In: VELHO, Gilberto; ALVITO, Marcos (Orgs.). Cidadania e violência. 2. ed. Rio de Janeiro: Editora Ufrj, Ed. FGV, 2000. p. 90-99.

MUNIZ, Jaqueline. Os direitos dos outros e outros direitos: um estudo sobre a negociação de conflitos nas Deams/RJ. In: SOARES, Eduardo (Org.). Violência e política no Rio de Janeiro. Rio de Janeiro: Iser/Relume Dumará, 1996. p. 125-163.

RIFIÓTIS, Theophilos. As delegacias especiais de proteção à mulher no Brasil e a "judiciarização" dos conflitos conjugais. Florianópolis, Ufsc, Programa de Pós-Graduação em Antropologia Social, 2003. (Antropologia em Primeira Mão, 58)

SAFFIOTI, Heleieth. Violência doméstica: questão de polícia e da sociedade. In: CORRÊA, Mariza et al. (Org.). Gênero e cidadania. Campinas: Pagu - Núcleo de Estudos de Gênero, 2002. p. 59-69. (Coleção Encontros)

SOARES, Bárbara Musumeci. Mulheres invisiveis: violência conjugal e as novas políticas de segurança. Rio de Janeiro: Civilização Brasileira, 1999.

SCHUCH, Patrice. Práticas de justiça: uma etnografia do "campo de atenção ao adolescente infrator" no Rio Grande do Sul, depois do Estatuto da Criança e do Adolescente. Porto Alegre, Universidade Federal do Rio Grande do Sul, Programa de Pós-Graduação em Antropologia Social, 2005. (Tese de doutorado)

VIEIRA, Miriam Steffen. Universo legal em ato: a construção de categorias jurídicas em torno da violência sexual. Tese (Doutorado) - Programa de Pós-Graduação em Antropologia Social, Universidade Federal do Rio Grande do Sul, Porto Alegre, 2007. 